\title{
PROSPEK PENGEMBANGAN AGROINDUSTRI KERUPUK SUKUN (STUDI KASUS DI DESA JAMBUIR KECAMATAN GAYAM KABUPATEN SUMENEP)
}

\author{
Wiwik Sri Untari ${ }^{*}$ ) Mohammad Jakfar Syadik2) \\ ${ }^{1}$ Program Studi Agribisnis, Fakultas Pertanian, Universitas Abdurachman Saleh Situbondo \\ 2Balai Penyuluhan Pertanian, Dinas Pertanian Tanaman Pangan, Holtikulutura dan \\ Perkebunan Sumenep \\ Email Korespondensi : wiwik_sri_untari@unars.ac.id
}

\begin{abstract}
Makanan adalah kebutuhan dasar bagi setiap individu. Makanan adalah hasil kerja keras banyak orang dalam suatu sistem yang mencakup kegiatan input, produksi, pengolahan, dan pemasaran bahan makanan (faktor output). Agro-processing produk pertanian adalah bagian dari agroindustri, yang mengolah bahan baku yang bersumber dari tanaman, hewan, dan ikan. Pemrosesan meliputi proses transformasi dan pelestarian melalui perubahan fisik atau kimia, penyimpanan, pengemasan, dan distribusi. Dari definisi ini, dapat dilihat bahwa pelaku agroindustri pengolahan agroindustri adalah petani yang berproduksi bersama konsumen atau pengguna produk agroindustri. Dengan demikian, agroindustri pengolahan pertanian memiliki karakteristik sebagai berikut: (a) meningkatkan nilai tambah, (b) menghasilkan produk yang dapat dipasarkan atau digunakan atau dimakan, (c) meningkatkan daya saing, dan (d) meningkatkan pendapatan dan keuntungan bagi produsen. Kecamatan Gayam adalah salah satu sentra produksi sukun. Berdasarkan statistik Sumenep, pada tahun 2015 produksi sukun di Kecamatan Gayam adalah 3.492. Sukun adalah tanaman komoditas yang dipasarkan keluar dari Sepudi dan juga diolah menjadi makanan khas pulau Sepudi, yaitu kerupuk sukun. Beberapa warga Desa Jambuir, Kecamatan Gayam, mengolah sukun menjadi kerupuk sukun. Bisnis industri kerupuk sukun yang berkembang di masyarakat adalah industri rumah tangga dan industri kecil. Mengolah sukun menjadi kerupuk sukun bertujuan untuk meningkatkan daya tahan buah sukun sehingga cocok untuk dikonsumsi dan mendapatkan nilai jual tinggi di pasaran. Kegiatan bisnis pengolahan sukun menjadi kerupuk sukun mengubah bentuk sukun dari produk primer menjadi produk baru dengan nilai ekonomi lebih tinggi.
\end{abstract}

Kata Kunci: Prospek Pengembangan, Agroindustri Sukun, Desa Gayam

\begin{abstract}
Food is a basic need for every individual. Food is a result of the hard work of many people in a system that includes activities for input, production, processing, and marketing of food ingredients (output factor). Agro-processing of agricultural products is part of agro-industry, which processes raw materials sourced from plants, animals, and fish. Processing includes the process of transformation and preservation through physical or chemical changes, storage, packing, and distribution. From this definition, it can be seen that agroindustry processing agroindustry players are among farmers who produce with consumers or users of agro-industry products. Thus, agricultural processing agroindustry has the following characteristics: (a) increase added value, (b) produce products that can be marketed or used or eaten, (c) increase competitiveness, and (d) increase income and profits for producer. Gayam Subdistrict is one of the breadfruit production centers. Based on Sumenep's statistics, in 2015 breadfruit production in Gayam sub-district was 3,492. Breadfruit is a commodity
\end{abstract}


plant that is marketed out of Sepudi and is also processed into a typical food of the Sepudi islands, namely breadfruit crackers. Some of the people of Jambuir Village, Gayam Subdistrict, process breadfruit into breadfruit crackers. Breadfruit cracker industry businesses that develop in the community are home industries and small industries. Processing breadfruit into breadfruit crackers aims to increase the durability of breadfruit fruit so that it is suitable for consumption and obtain a high selling value in the market. The business activities of processing breadfruit into breadfruit crackers change the shape of breadfruit from primary products to new products with higher economic value.

Key Words: Development Prospects,Breadfruit Agroindustry, Gayam Village

\section{PENDAHULUAN}

Agroindustri pengolahan hasil pertanian merupakan bagian dari agroindustri, yang mengolah bahan baku yang bersumber dari tanaman, binatang dan ikan. Pengolahan yang dimaksud meliputi pengolahan berupa proses transpormasi dan pengawetan melalui perubahan fisik atau kimiawi, penyimpanan, pengepakan, dan distribusi. Saat ini konsep pertanian sudah mengarah pada pencapaian produk yang menghasilkan nilai profit. Berbeda dengan konsep dahulu yang masih mengarah pada product driven agriculture. Perubahan konsep tersebut dikarenakan perkembangan jaman yang mengharuskan petani untuk mencapai produksi dengan member nilai tambah sebagai pemenuhan kebutuhan dan dari permintaan konsumen, sehingga petani tidak harus berhenti pada usaha tani saja namun berusaha untuk dapat member nilai tambah pada hasil produknya.

Kecamatan Gayam merupakan salah satu sentra produksi sukun. Sukun menjadi tanaman komoditi yang dipasarkan keluar Sepudi dan juga di olah benjadi makanan khas kepulauan sepudi yaitu kerupuk sukun. Kerupuk sukun merupakan makanan khas kepulauan sepudi. Di Desa Jambuir Kecamatan Gayam sebagian masyarakatnya mengolah sukun menjadi kerupuk sukun. Usaha industri kerupuk sukun yang berkembang dimasyarakat adalah industri rumah tangga dan industri kecil. Pengolahan sukun menjadi krupuk sukun bertujuan untuk meningkatkan keawetan buah sukun sehingga layak untuk dikonsumsi dan memperoleh nilai jual yang tinggi dipasaran. Dengan adanya kegiatan usaha pengolahan sukun menjadi kerupuk sukun yang mengubah bentuk dari produk primer menjadi produk baru yang lebih tinggi nilai ekonomisnya. Permasalahan yang dapat dirumuskan dari uraian di atas yaitu: Berapa tingkat efisiensi dan besar nilai tambah dari Agroindustri kerupuk sukun di Desa Jambuir Kecamatan Gayam, Kabupaten Sumenep.

\section{METODE PENELITIAN}

\section{Penentuan Daerah Peneliti}

Penentuan daerah penelitian dilakukan secara sengaja (Purposive Method). Nazir (1999) mengatakan bahwa yang dilakukan dengan mengambil orang-orang yang memiliki cirri-ciri spesifik yang dimiliki oleh sampel. Daerah yang di pilih untuk penelitian adalah Desa Jambuir, Kecamatan Gayam, Kabupaten Sumenep, daerah ini dipilih karena terdapat pengusaha agroindustri krupuk sukun. Penelitian ini akan mendiskripsikan berbagai fenomena yang akan dihadapi oleh produsen khususnya mengenai tingkat efesiensi dan nilai tambah yang di dapat dari usaha krupuk sukun.

\section{Metode Dasar Penelitian}

Penelitian ini menggunakan metode survey deskriptif dan kuantitatif. Metode survey diartikan sebagai metode yang digunakan dalam penyelidikan untuk memperoleh fakta dari gejala yang ada dan mencari keterangan faktual suatu kejadian dari gejala yang ada dan mencari keterangan faktual suatu kejadian atau situasi dari suatu kelompok atau daerah. Pendekatan yang dilakukan untuk memecahkan permasalahan adalah melalui pendekatan literatur, surye melalui wawancara dengan perangkat kuesioner, wawancara 
mendalam (indepth interview) (Masyhuri, 2008). Kuantitatif secara sederhana dapat diartikan sebagian data yang didalamnya berisi bilangan atau angka yang memiliki sifat berfareatif pada nilainya.

\section{Populasi Dan Sampel}

Menurut Sugiyono (2007), teknik pengambilan sampel yang digunakan adalah Sampling Jenuh (sensus) yaitu penentuan sampel bila semua anggota populasi digunakan sebagai sampel, hal ini digunakan bila jumlah populasi relatif kecil, kurang dari 30 orang, penelitian yang ingin membuat generalisasi dengan kesalahan yang sangat kecil. Populasi yang mengolah buah sukun menjadi krupuk sukun di Desa Jambuir Kecamatan Gayam Kabupaten Sumenep 12 agroindustri, sehingga 12 agroindustri yang mempemproduksi krupuk sukun dijadikan sampel.

\section{Teknik Pengumpulan Data}

Teknik pengumpulan data yang digunakan dalam penelitian ini adalah menggunakan data primer dan sekunder.Data primer merupakan data yang didapatkan melalui wawancara, pengukuran, dan pengamatan langsung di lapangan.Data sekunder adalah pengumpulan data yang dilakukan melalui studi kepustakaan yang terdiri dari mengumpulkan buku, karya ilmiah, makalah yang memiliki relevansi dengan masalah Agroindustri kerupuk sukun. Teknik Pengumpulan data dalam penelitian ini dilakukan dengan cara sebagai berikut:

1. Kuesioner (Quetionaire) adalah suatu cara pengumpulan data dengan cara memberikan daftar pertanyaan yang telah disediakan kepada responden yaitu pengusaha Agroindustri kerupuk sukun.

2. Wawancara adalah proses memperoleh data dengan cara tanya jawab secara langsung dengan pengusaha Agroindustri kerupuk sukun. Pengumpulan data seperti ini dituntut untuk melakukan banyak pelacakan guna mendapatkan data yang lebih dalam dan rinci.

3. Observasi (Observation) adalah pengamatan langsung pada objek yang akan diteliti untuk mendapatkan gambaran yang tepat mengenai objek penelitian.

\section{Teknik Analisa Data}

1. Untuk hipotesis 1, untuk mengetahui efisiensi usaha agroindustri krupuk sukun menggunakan beberapa perhitungan yaitu analisis biaya, penerimaan, pendapatan, dan analisis efisiensi usaha.

a. Untuk biaya total dapat dihitung dengan mengunakan rumus sebagai berikut :

$$
\mathrm{TC}=\mathrm{TFC}+\mathrm{TVC}
$$

Keterangan :

$\mathrm{TC}=$ Biaya total usaha Agroindustri krupuk sukun(Rp)

TFC = Biaya tetap usaha Agroindustri krupuk sukun (Rp)

TVC = Biaya variabel usaha Agroindustri krupuk sukun(Rp)

b. Untuk menghitung penerimaan dapat dihitung dengan menggunakan rumus sebagai berikut :

$$
\mathrm{TR}=\mathrm{Q} \times \mathrm{P}
$$


Keterangan :

TR = Penerimaan total usaha Agroindustri krupuk sukun (Rp)

$\mathrm{Q}=$ Jumlah produk krupuk sukun( Bungkus)

$\mathrm{P}=$ Harga produk krupuk sukun (Rp)

c. Menghitung Pendapatan Usaha Pengolahan Krupuk sukun

$$
\pi=\mathrm{TR}-\mathrm{TC}
$$

\section{Keterangan :}

$\pi=$ Keuntungan usaha Agroindustri krupuk sukun (Rp)

$\mathrm{TR}=$ Penerimaan usaha Agroindustri krupuk sukun(Rp)

$\mathrm{TC}=$ Biaya total usaha Agroindustri krupuk sukun(Rp)

d. Efisiensi usaha dapat dihitung dari perbandingan antara besarnya penerimaan dan biaya yang digunakan untuk berproduksi yaitu dengan menggunakan R/C Ratio:

Efisiensi $=\frac{R}{C}$

Keterangan :

$\mathrm{R}=$ Penerimaan usaha agroindustri kerupuk sukun $(\mathrm{Rp} / \mathrm{kg})$

$\mathrm{C}=$ Biaya total usaha agroindustri kerupuk sukun $(\mathrm{Rp} / \mathrm{kg})$

Kriteria yang digunakan dalam penentuan efisiensi usaha adalah :

a. $\mathrm{R} / \mathrm{C}>1$ berarti usaha agroindustri kerupuk sukun yang dijalankan sudah efisien,

b. $\mathrm{R} / \mathrm{C}=1$ berarti usaha agroindustri kerupuk sukun belum efisien atau usaha mencapai titik impas,

c. $\mathrm{R} / \mathrm{C}<1$ berarti usaha agroindustri kerupuk sukun yang dijalankan tidak efisien.

Untuk hipotesis 2, diuji untuk melihat bagaimana nilai tambah yang diperoleh dari agroindustri kerupuk sukun, digunakan dengan pengukuran nilai tambah metode Hayami.

Jika rasio nilai tambah $>50 \%$ maka nilai tambah tersebut tergolong tinggi (positi), apabila $<50 \%$ maka nilai tambah tergolong rendah (negative).

Dari hasil perhitungan tersebut akan diperoleh keterangan sebagai berikut:

1. Perkiraan nilai tambah (dalam rupiah).

2. Rasio nilai tambah terhadap nilai produk yang dihasilkan (dalam \%).

3. Imbalan bagi modal dan manajemen (keuntungan yang diterima perusahaan) dalam rupiah (Sudiyono, 2004).

\section{HASIL DAN PEMBAHASAN \\ Profil Perusahaan}

Kerupuk sukun merupakan olahan krupuk berbahan buah sukun. Di sepudi kerupuk sukun merupakan produk yang di produksi rumahan, 12 agroindustri yang pendapatannya bergantung pada pembuatan produk tersebut. Kerupuk sukun berbentuk 
bundar yang memiliki warna khas kerupuk sukun mepunyain warna dasar kuning dan memiliki Rasa lemak yang ditambahkan aroma bawang putih dan kencur. Proses pembuatannya dengan cara sederhana / tradisional tidak mengunakan alat produksi masa kini dan tanpa menggunakan bahan pemgawet kimia. Kerupuk sukun jika disimpan pada tempat kedap udara dapat bertahan selama ennam bulan.

\section{Proses Produksi Kerupuk Sukun}

Proses pembuatan kerupuk sukun mulai bahan baku mentah sampai siap dijual melalui beberapa tahapan sebagai berikut:

a. Pengupasan Kulit Sukun yang matang.

b. Pencucian sukun yang telah dikupas dicuci dengan air hingga seluruh kotoran bersih. Kemudian, dibilas dengan air bersih sehingga kotoran dan getah yang melekat benar-benar bersih.

c. Dibelah menjadi 4 bagian danbuang hati sukunnya, tujuannya agar nantinya tidak mengeluarkan getah lagi.

d. kemudian di kukus kuranglebih 40 menit.

e. Setelah matang angkat dan pindahkan ke tampa yang sudah disiapkan, haluskan secepatnya jangan sampai dingin, tambahkan bumbu-bumbu yang dibutuhkan.

f. Gepengkan sukun yang telah dihaluskan, kemudian dicetak. Tata pada tikar yang terbuat dari daun siwalan atau disebut juga dengan tikar rakara. Kemudian di jemur pada terikmatahari.

g. Setelah kering dilakukan pengemasan.

h. Kerupuk sukun yang dikemas dalam plastik dapat tahan simpan selama 4-6 bulan.

\section{Analisis Agroindustri Krupuk Sukun \\ Biaya Produksi}

Biaya produksi adalahakumulasi dari semua biaya-biaya yang dibutuhkan dalam proses produksi dengan tujuan untuk menghasilkan suatu produk atau jasa biaya ini meliputi biaya tetap dan biaya variable. Rata-rata biaya dalam satukali produksi agroindustri kerupuk sukun di Desa Jambuir Kecamatan Gayam Kabupaten Sumenep dapat dilihat pada tabel 1.

Tabel 1. Rata-Rata Biaya total dalam satu kali produksi agroindustri kerupuk sukun di Desa Jambuir Kecamatan Gayam Kabupaten Sumenep

\begin{tabular}{lll}
\hline No. & Biaya Usaha & Biaya (Rp) \\
\hline 1. & Biaya Tetap & Rp. $\quad 762.91$
\end{tabular}

2. Biaya Vareabel

Rp. $130.817,17$

\begin{tabular}{lc}
\hline Jumlah & Rp. $131.580,08$ \\
\hline
\end{tabular}

Dari tabel diatas dapat dilihat bahwa dalam satukali proses produksi usaha agroindustri kerupuk sukun di Desa Jambuir Kecamatan Gayam Kabupaten Sumenup memilik biaya total sebesar Rp. 131.580,08. Biaya total tersebut didapat dari haril penjumlahan biaya tetap dengan biaya vareabel. Alat-alat yang digunakan dalam produksi kerupuk sukun yaitu tikar, pisau, ember, tampa, penumbuk, dangdang, kompor/tungku, gas, dan steples. 
Biya tetap agroindustri kerupuk sukun didapat dari biaya penyusutan alat per hari sebesar Rp. 762,91. Biayavareabel agroindustri kerupuk sukun didapat dari penjumlahan biaya sarana produksi,biaya penunjang dan biaya tenaga kerja sebesar Rp. 130. 817,17.

\section{Penerimaan}

Penerimaan adalah jumlah uang yang dapat dari hasil produksi yang masih belum dikurangi biaya total.penerimaan didapat dari jumlah hasil produksi dikali harga satuan produk. Dalam usaha agroindustri krupuk sukun di Desa Jambuir Kecamatan Gayam Kabupaten Sumenep memiliki pendapatan rata-rata sebesar Rp. 256.666,67 dengan harga satuan produk sebesar Rp. 8.000.

\section{Pendapatan}

Pendapatan yaitu jumlah nilai uang yang diperoleh pelaku usaha,setelah penerimaan dikurangi dengan seluruh biaya atau biaya total.oleh karna itu pendapatan usaha disebut juga sebagai laba usaha. Rata-rata pendapatan yang di dapat dari agroindustri kerupuk sukun di Desa Jambuir Kecamatan Gayam Kabupaten Sumenep dapat dilihat di tabel 1:

Tabel 2. Rata-Rata Pedapatan dalam satu kali produksi Agroindusti Kerupuk Sukun di Desa Jambuir Kecamatan Gayam Kabupaten Sumenep

\begin{tabular}{lll}
\hline No. & Uraian & Nilai (Rp) \\
\hline 1. & Penerimaan ( TR) & Rp. 256.666,67 \\
2. & Total Biaya ( TC) & Rp. $131.580,08$ \\
\hline \multicolumn{2}{l}{ Pendapatan } & Rp. $125.086,59$ \\
\hline
\end{tabular}

Tabel 2 dapat dilahat bahwa dalam satu kali produksi usaha agroindustri kerupuk sukun di Desa Jambuir Kecamatan Gayam Kabupaten Sumpenep memiliki penerimaan sebesar Rp.256.666,67 dan biaya total sebesar Rp.132.580,08 sehingga pendapatan atau laba yang di dapat dari agroindustri krupuk sukun sebesar Rp. 125.086,59.

\section{Efisiensi}

Efisiensi usaha dapat dihitungan dari perbandingan atara besarnya penerimaan dengan biaya yang digunakan untuk memptoduksi yaitu dengan menggunakan R/C Ratio. Efisiensi usaha agroindustri kerupuk sukun di Desa Jambuir Kecamatan Gayam Kabupaten Sumenep dapat di lihat ditabel 2.

Tabel 3. Efisiensi Usaha Agroindustri Kerupuk Sukun dalam satu kali produksi, di Desa Jambuir Kecamatan Gayam Kabupaten Sumenep

\begin{tabular}{llll}
\hline No. & Uraian & Satuan & Nilai \\
\hline 1. & Penerimaan & Rp. & $256.666,67$ \\
2. & Total Biaya & Rp. & $131.580,08$ \\
\hline R/C Ratio & & 1,95 \\
\hline
\end{tabular}

Dari tabel diatas dapat dilihat bahwa $\mathrm{R} / \mathrm{C}$ rasio usaha agroindustri kerupuk sukun di Desa Jambuir Kecamatan Gayam Kabupaten Sumenep mencapai r/c ratio 1,95 hal ini disebabkan karena penerimaan yang di peroleh sebesar Rp. 256.666,67 dan biaya yang dikeluarkan sebesar Rp. 131.580,08. R/C ratio didapat dari pembagian antara penerimaan dengan biaya total sehingga diperoleh $\mathrm{R} / \mathrm{C}$ Ratio rata-rata 1,95. Artinya setiap Rp. 1,00 biaya yang dikeluarkan akan memberikan keuntungan sebesar Rp. 1,95. 


\section{Nilai Tambah}

Nilai tambah merupakan pertambahan nilai suatu barang atau komuditas yang sudah melewati proses pengolahan,pengangkutan atau juga proses penyimpanan yang merupakan tahap dalam proses prosduksi. Nilai tambah yang didapat dalam proses prosduksi usaha agroindustri krupuk sukun di Desa Jambuir Kecamatan Gayam Kabupaten Sumenep dapat dilihat di tabel 4:

Tabel 4. Nilai Tambah Agroindustri Kerupuk Sukun di Desa Jambuir Kecamatan Gayam Kabupaten Sumenep

\begin{tabular}{|c|c|}
\hline Variabel & Nilai \\
\hline \multicolumn{2}{|l|}{ Output, Input dan Harga } \\
\hline 1. Output (Kemasan/1 Kali Produksi) & 32,08 \\
\hline 2. Bahan baku (Buah/ 1 Kali Produksi) & 17,67 \\
\hline 3. Tenaga kerja (HKP/Hari) & 1,72 \\
\hline 4. Faktor konversi $(1: 2)$ & 1,82 \\
\hline 5. Koefisien tenaga kerja $(3: 2)$ & 0,1 \\
\hline 6. Harga output (Rp/Kemasan) & 8.000 \\
\hline 7. Upah rata-rata tenaga kerja (Rp/HKP) & $21.666,67$ \\
\hline \multicolumn{2}{|l|}{ Pendapatan dan Keuntungan (Rp/bahan baku) } \\
\hline 8. Harga bahan baku(Rp/Buah) & 3.000 \\
\hline 9. Harga input lain (Rp/Buah) & $1.689,2$ \\
\hline 10. Nilai output $(4 \times 6)$ & 14.560 \\
\hline 11. a. Nilai tambah $(10-8-9)$ & $9.870,8$ \\
\hline b. Rasio nilai tambah [(11a:10)×100\%] & 67,79 \\
\hline 12. a. Imbalan tenaga kerja $(5 \times 7)$ & $2.166,67$ \\
\hline b. Bagian tenaga kerja [(12a:11a)×100\%] & 21,95 \\
\hline 13. a. Keuntungan $(11 a-12 a)$ & $7.704,13$ \\
\hline b. Tingkat keuntungan [(13a:10)×100\%] & 52,91 \\
\hline \multicolumn{2}{|l|}{ Balas Jasa Pemilik Faktor Produksi } \\
\hline \multirow{4}{*}{ 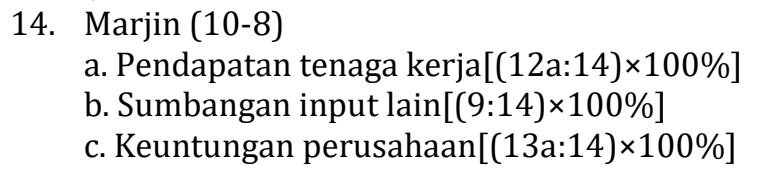 } & 11.560 \\
\hline & 18,74 \\
\hline & 14,61 \\
\hline & 66,64 \\
\hline
\end{tabular}

Berdasarkan tabel 4 dapat diketahui bahwa rata-rata jumlah otput yang di hasilkan adalah sebesar 32,08 kemasan kerupuk sukun dengan mengolah buah sukun sebanyak 17,67 buah. Sehingga faktor konversi yang didapat adalah sebesar 1,82.

Konvensi ini menunjukkan bahwa setiap penggunaan 1 buah sukun akan menghasilka 1,82 kemasan kerupuk sukun. Koefisien tenaga kerja menunjukkan input tenaga kerja yang dibutuhkan untuk memproduksi 1 buah sukun menjadi kerupuk sukun. Hasil konfensi tenaga kerja menunjukkan bahwa rata-rata kebutuhan input tenaga kerja untuk mengolah 1 buah sukun adalah 0,1 jam/buah.

Nilai tambah yang diperoleh dari pengolahan 1 buah sukun menjadi kerupuk sukun adalah Rp. 9.870,8/1,82 kemasan. Jadi setiap produksi 1 buah sukun menjadi kerupuk sukun 1,82 kemasan adalah sebesar RP. 9.870,8. Nilai tambah ini diperoleh dari pengurangan nilai produk dengan harga bahan baku dan input lain. Rasio nilai tambah 
yang diperoleh adalah 67,79\%.Hal ini berarti dalam pengolah buah sukun menjadi kerupuk sukun memberikan nilai tambah sebesar $67,79 \%$ dari nilai produk.

Pendapatan tenaga kerja agroindustri kerupuk sukuk didapat dari perkalian koefisien tenaga kerja dengan upah rata-rata tenaga kerja yaitu sebesar Rp 21.666,67. Pendatan tenaga keraja didapat dari kofesiendi tenaga kerja dikaliakan dengan upah ratarata tenaga kerja yaitu sebesar Rp. 2.166,67.Persentase pendapatan tenaga kerja pendapatan tenaga kerja tehadap nilai tambah yaitu 21,95\%. Keuntungan diperoleh dari pengurangan nilai tambah dengan imbalan tenaga kerja besar keuntungannya adalah Rp.7.704,13 atau tingkat keuntungan sebesar 52,91\% dari nilai produk. Keuntungan ini menunjukkan total yang diperoleh dari setiap pongolahan buah sukun menjadi kerupuk sukun.

Hasil analisa nilai tambah ini juga dapat menunjukkan marjin dari bahan baku buah sukun menjadi kerupuk sukun yang didistribusikan kepada pendapatan tenagakerja, sumbangan imputlain, dan keuntungan perusahaan. Marjin ini menunjukkan selisih antara nilai produk dengan harga bahan baku buah sukun, setiap pengolahan 1 buah sukun menjadi kerupuk sukun diperoleh marjin Rp. 11.560 yang didistribusikan untuk masing masing faktor tenaga kerja yaitu pendapatan tenaga kerja sebesar $18,74 \%$, sumbangan imputlain sebesar 14,61\% dan keuntungan perusahaan $66,64 \%$.

\section{KESIMPULAN}

Berdasarkan hasil penelitian yang telah dilakukan pada Agroindustri kerupuk sukun di Desa Jambuir, Kecamatan Gayam, Kabupaten Sumenep dapat diperoleh kesimpulan sebagai berikut :

1. Total biaya yang dikeluarkan oleh agroindustri kerupuk sukun sebesar Rp. $131.580,08$ per satu kali produksi. Penerimaan yang diperoleh agroindustri ratarata sebesar Rp. 256.666,67 per satu kali produksi. Keuntungan yang diperoleh pengusaha rata-rata sebesar Rp.125.086,59 per satu kali produksi.

2. Usaha agroindustri kerupuk sukun sudah efisien karena memiliki nilai R/C rasio sebesar 1,95 berarti bahwa dalam setiap Rp.1,00 biaya yang dikeluarkan dalam usaha agroindustri kerupuk sukun memberikan penerimaan sebesar 1,95 kali dari biaya yang telah dikeluarkan.

3. Nilai tambah yang dinikmati pengusaha dari agroindustri sebesar Rp. 9.870,8 per buah bahan baku yang dimanfaatkan dengan rasio nilai tambah sebesar 67,79\% sehingga nilai tambah dalam pengolahan kerupuk sukun positif. Nilai tambah ini merupakan keuntungan yang didapatkan oleh agroindustri kerupuk sukun dalam 1 buah penggunaan bahan baku.

\section{REFERENSI}

Badan Pusat Statistik. 2015. Sumenep Dalam Angka 2015. Sumenep.

Baroh, I. 2007 Analisis Nilai Tambah dan Distribusi Kripik Nangka Studi Kasus pada Agroindustri Keripik Nangka di Lumajang. LP UMM, Malang.

Departemen Pertanian. 2003. Panduan Teknologi Pengolahan Sukun Sebagai Bahan Pangan Alternatif. Direktorat Pengolahan dan Pemasaran Hasil Holtikultura. Jakarta

Firdaus. M. 2009. Manajemen Agribisnis. PT Bumi Aksara, Jakarta

Gaspersz, V. 2001. Ekonomi Manajerial: Pembuatan Keputusan Bisnis. PT. Gramedia Pustaka Utama, Jakarta 
Hayami Y, Kawagoe T, Morooka Y, Siregar M. 1987. Agricultural Marketing and Processing in Upland Java. A Perspective from a Sunda Village. Bogor: The CPGRT Centre.

Hayami, et. al. 1987. Agricultural Marketing and Processing in Upland Java. A Perspective From A Sunda Village. CGPRT, Bogor.

Kartono, G.,Harwanto, Suhardjo dan T. Purbiati. 2004. Keragaman Kultivar Sukun dan Pemanfaatannya di Jawa Timur (Studi kasus di Kabupaten Kediri dan Banyuwangi). http://www.bptp-jatim-deptan.go.id. Diakses pada tanggal 26 Maret 2018

Kurniawan Dwi A. P. 2015 Analisis Nilai Tambah dan Strategi Pengembangan Kopi Luwak (studi kasus Desa Kayumas Kecamatan Arjasa Kabupaten Situbondo)

Lipsey, G. R. Peter, O. P. dan Douglas, D. P. 1990 Pengantar Mikroekonomi I jilit I. Diterjemahkan oleh Jaka, A. W dan Kirbrandoko. Erlangga. Jakarta

Manullang, K. 1990. Pengukuran Produktivitas Dengan Metode Nilai Tambah. Pusat Produktivitas Nasional, Jakarta.

Marimin dan Maghfiroh N. 2010. Aplikasi Teknik Pengambilan Keputusan dalam Manajemen Rantai Pasok. PT. Remaja Rosdakarya, Bandung

Masyhuri dan M. Zainuddin. 2008. Metode Penelitian Sosial dan Ekonomi, Teori dan Aplikasi. Penerbit Alfabeta. Bandung

Moh., Nazir, 1999, Metode Penelitian, Cetakan Ketiga, Jakarta, Ghalia Indonesia

Nicholson, W. 1992. Mikroekonomi Intermediate dan Penerapannya. Erlangga. Jakarta.

Purwantoyo, Eling. 2007. Budidaya dan Pasca Panen Sukun. Aneka Ilmu. Semarang

Pitojo, S. 1992. Budidaya Sukun. Kanisius. Yogyakarta.

Rahardja. P dan Manurung. M. 2006. Teori ekonomi mikro suatu pengantar. Fakultas Ekonomi Universitas Indonesia: Jakarta

Soekartawi. 1995. Analisis Usahatani. UI-Press. Jakarta.

Sudiyono. 2002. Pemasaran Pertanian. Universitas Muhammadia Malang. Malang: UMM Press

Sugiyono. 2007. Metonde Penelitaan Kuantitatif Kualitatif dan R\&D. Bandung: Alfabeta

Suratiyah, K. 2002. Ilmu Usahatani. Penebar Swadaya: Bogor

Sutawi. 2002. Manajemen Agrobisnis. Malang: UMM Press..

Valentina 0. 2009 Analisis Nilai Tambah Ubi Kayu Sebagai Bahan baku Keripik Singkong Karanganyar.

Widowati, S. 2003. Prospek Tepung Sukun Untuk Berbagai Produk Makanan Olahan Dalam Upaya Menunjang Diversifikasi Pangan. http://tumotou.net/70207134/sri_widowati. htm, diakses pada tanggal. 1 April 2018

Wikipedia. 2008. Sukun. Dalam http//;id.wikipedia.org diakses pada tanggal 23 maret 2018

Zulkifli. 2012. Analisis Pendapatan Dan Nilai Tambah Pada Agroindustri Kripik Ubi di Kecamatan Tanah Luas Kabupaten Aceh Utara 